Article

\title{
Insufficient Oral Behaviour and the High Need for Periodontal Treatment in Patients with Heart Insufficiency and after Heart Transplantation: A Need for Special Care Programs?
}

\author{
Christian Binner ${ }^{1,+} \mathbb{D}$, Justus Wagner ${ }^{2,+}$, Gerhard Schmalz ${ }^{2}$, Mirjam Eisner ${ }^{2}$, Josephine Rast ${ }^{2}$, \\ Tanja Kottmann ${ }^{3}$, Rainer Haak ${ }^{2}$, Andreas Oberbach ${ }^{4}$, Michael A. Borger ${ }^{1}$, Jens Garbade ${ }^{1, \ddagger}$ (D) \\ and Dirk Ziebolz ${ }^{2, *, \ddagger(\mathbb{D})}$ \\ 1 Department of Cardiac Surgery, Leipzig Heart Center, University of Leipzig, 04289 Leipzig, Germany; \\ Christian.Binner@leipzig-heart.de (C.B.); michael.borger@helios-gesundheit.de (M.A.B.); \\ Jens.Garbade@medizin.uni-leipzig.de (J.G.) \\ 2 Department of Cariology, Endodontology and Periodontology, University of Leipzig, \\ 04103 Leipzig, Germany; justus7@gmx.de (J.W.); gerhard.schmalz@medizin.uni-leipzig.de (G.S.); \\ mirjamcharlotte@web.de (M.E.); josephine.rast@medizin.uni-leipzig.de (J.R.); \\ rainer.haak@medizin.uni-leipzig.de (R.H.) \\ 3 CRO Dr. med. Kottmann GmbH \& Co. KG, 59077 Hamm, Germany; tk@cro-kottmann.de \\ 4 Department of Diagnostics, Fraunhofer Institute for Cell Therapy and Immunology Leipzig, \\ 04103 Leipzig, Germany; Andreas.Oberbach@medizin.uni-leipzig.de \\ * Correspondence: dirk.ziebolz@medizin.uni-leipzig.de; Tel.: +49-341-97-21211; Fax: +49-341-97-21219 \\ + These authors contributed equally as the first author. \\ $\ddagger$ These authors are equally contributing senior authors.
}

Received: 25 September 2019; Accepted: 10 October 2019; Published: 12 October 2019

\begin{abstract}
Background: The aim of this cross-sectional study was the assessment of dental behaviour and oral health condition of heart transplant recipients (HTx) in comparison to patients with heart insufficiency (HI). Methods: Patients attending the Department for Cardiac Surgery, Leipzig Heart Center, Germany were recruited. Standardized questionnaires regarding dental behaviour and periodontal complaints were applied. A dental (decayed-, missing- and filled-teeth index) and periodontal examination (periodontal probing depth (PPD) and clinical attachment loss (CAL)) was performed. Based on the oral findings, dental and periodontal treatment need was determined. Statistics: T-test, Mann-Whitney U test, Chi-square test, and Fisher-test $(p<0.05)$. Results: A total of 201 patients (HTx: 112, HI: 89) were included. HTx patients were significantly more often allocated to dentists $(p<0.01)$. Furthermore, the HTx patients rated feeling informed appropriately about oral health more often $(p<0.01)$. HTx patients used interdental cleaning $(p<0.01)$ and mouth rinse $(p=0.02)$ more often than HI patients. No differences between groups were present regarding dental status and periodontitis severity $(p>0.05)$. Periodontal treatment need was high, showing prevalence of $79.5 \%$ (HTx) and $87.6 \%$ (HI, $p=0.14$ ), respectively. Conclusions: Both groups show insufficient oral behaviour and a high need for periodontal treatment. Special care programs for HTx candidates and recipients appear recommendable.
\end{abstract}

Keywords: dental care; heart transplantation; oral health; dental behaviour

\section{Introduction}

Heart transplantation has developed into preferred therapy for selected patients with end-stage heart failure. Besides the increasing success of this therapy, long-term complications are still a very 
important issue [1]. Thereby, infectious complications, renal failure, and malignancy frequently occur as a consequence of their necessary life-long immunosuppression [1,2]. The reduction of these long-term complications of immunosuppressive therapy by different strategies seems an important issue to improve individual care of heart transplant recipients [2,3].

The oral cavity is an important habitat for bacteria and simultaneously an important source for bacteria which enter the systemic circulation of patients [4]. These bacteria have the potential to cause serious infectious complications in immunocompromised individuals [5]. Accordingly, patients should receive a comprehensive dental rehabilitation prior to transplantation, including periodontal and dental therapy, to minimize the risk of systemic infections in these vulnerable patient groups [6]. Thereby, the adequate assessment and care by a qualified specialist and application of a structured post-transplant follow-up program seems recommendable to avoid oral disease-related systemic complications in transplant recipients [6]. In contrast to these recommendations, patients before and after organ transplantation (kidney, liver, lung) were reported to show an insufficient oral status, especially with a high prevalence of periodontal disease [7-10]. Moreover, transplant recipients in different German transplant centres were found to present a high dental and especially periodontal treatment need, irrespectively of the time since transplantation [11]. This indicates that recently the upper mentioned recommendations would be not fulfilled. Data for heart transplant recipients are still rare in the literature. A recent Chinese cross-sectional study presented worse periodontal conditions for heart transplant recipients [12]. It was also shown that periodontal inflammation would be associated with systemic inflammatory parameters in heart transplanted individuals [13]. However, data regarding the state of dental care of heart transplant recipients as well as their oral behaviour, especially compared to patients suffering from heart insufficiency in Germany, are not available yet. These insights might be helpful to detect current deficits in dental care of these patients and might deliver potential approaches to improve this situation.

Therefore, the current study aimed to assess dental behaviour, periodontal complaints, and the dental and periodontal condition of heart transplant recipients (HTx) in comparison to patients suffering from heart insufficiency (HI). Moreover, potential associations between periodontal complaints and clinically assessed treatment need should be investigated to estimate the ability to apply such a questionnaire-based screening in care of the patients. It was hypothesised that oral behaviour as well as dental and periodontal conditions would be insufficient in both HTx recipients and patients with HI.

\section{Methods}

This study was designed as a cross-sectional study to assess and compare the dental behaviour as well as oral health parameters of patients with heart insufficiency (HI) and after heart transplantation (HTx). The study has been reviewed and approved by the ethics committee of the Medical Faculty of University of Leipzig (No: 414/16-ek). All included participants were informed verbally and in writing and provided their written informed consent.

\subsection{Patients}

Patients attending the University Department for Cardiac Surgery, Heart Center Leipzig, Germany for their regular follow-up appointments were informed about aims and course of the investigation and asked for their voluntarily participation in the current study. Mandatory criteria for inclusion were the ability to provide informed consent and age of at least 18 years. The following exclusion criteria were defined:

- Clinical examination impossible due to worse general health status;

- Autoimmune diseases (e.g., rheumatoid arthritis, chronic inflammatory bowel diseases);

- Infectious diseases including hepatitis A, B, C, tuberculosis, or HIV;

- Addiction (alcohol or drugs);

- Pregnancy. 
Patients who fitted into the in- and exclusion criteria and provided informed consent were allocated to the questionnaire-based and oral examination. Furthermore, general and clinical data were extracted from medical history of the participants. Thereby, smoking habits (smoker: currently smoking, former smoker: smoking within five years before examination, nonsmoker: no smoking for at least five years), underlying heart diseases, comorbidities, relevant medications, and current blood parameters were extracted, if applicable.

\subsection{Questionnaires}

Two different standardized questionnaires were applied to the included participants. On the one hand, a periodontitis questionnaire, which assessed periodontitis-related complaints, was used as described previously [14]. On the other hand, a specific questionnaire, used in previous studies of this working group, regarding dental behaviour, including utilization of dental offers, oral hygiene procedures as well as disease related issues was used [8-10].

\subsection{Oral Examination}

The oral examination was performed once under standardized conditions at the Department of Cardiothoracic Surgery, Leipzig Heart Centre, Leipzig, Germany. The dental and periodontal investigation was executed by two experienced and calibrated dentists (kappa $>0.8$ ). Prior to dental and periodontal examination, participants received an antibiotic prophylaxis ( $2 \mathrm{~g}$ Amoxicillin) or clindamycine according to the recent guidelines [15].

At first an examination of the oral mucosa was performed to detect gingival overgrowth or any kind of changes of oral mucosa. The dental investigation comprised the assessment of teeth showing a carious cavitation of the tooth surface (D-T), missing teeth (M-T) as well as teeth restored with a filling or crown (F-T). According to WHO, the DMF-T index was assessed [16]. Based on the presence of carious lesions deserving dental intervention ( $\mathrm{D}-\mathrm{T}>0)$, dental treatment need was defined.

The periodontal examination included the evaluation of periodontal probing depth (PPD) and clinical attachment loss (CAL) with a periodontal probe (PCP 15, Hu-Friedy, Chicago, IL, USA). Based on these parameters, periodontitis severity according to Eke et al. 2012 was categorized into no/mild, moderate, or severe periodontitis [17]. Furthermore, the presence of PPD $\geq 3.5 \mathrm{~mm}$ in at least two different sextants was defined as periodontal treatment need in accordance to periodontal-screening index (PSI) [18,19]. Patients showing dental and/or periodontal treatment needs were classified as having "overall treatment need".

\subsection{Statistical Analysis}

The statistical analysis was performed with SPSS for Windows, version 24.0 (SPSS Inc., Chicago, Illinois, USA). The metric variables were tested for their normal distribution with Kolmogorov-Smirnov test. For comparison of two independent, normal distributed samples, a T-test was applied, after testing for homogeneity of variances with Levene test. In case of homogeneity of variances, Student's $\mathrm{t}$-test was used. In case of non-normal distribution, Mann-Whitney $U$ test was applied. The categorical data were analysed with Chi-square or Fisher-test, respectively. For all applied analyses, a two-sided significance testing was used, whereby the significance level has been set at $p<0.05$.

\section{Results}

\subsection{Patients}

A total of 201 patients were included in the current study, from which 112 participants were after HTx (mean age: $56.15 \pm 12.23$ years, average time since HTx: $7.1 \pm 5.50$ years) and 89 were HI patients (mean age $55.47 \pm 10.91$ years; $p=0.22$ ). In the HI group, more patients were smokers compared to HTx group $(p=0.02)$. Regarding underlying heart disease, co-morbidities, medication, and blood 
concentration of leucocytes and c-reactive protein (CRP), several differences were found between HTx and HI group $\left(p_{i} \leq 0.01\right.$; Table 1$)$.

Table 1. Patient characteristics, significance level: $p<0.05$.

\begin{tabular}{|c|c|c|c|c|}
\hline & & $\operatorname{HTx}(n=112)$ & HI $(n=89)$ & $p$-Value \\
\hline \multicolumn{2}{|c|}{ Gender (female in \% $(n)$ ) } & $23.2 \%(26)$ & $15.7 \%(4)$ & 0.22 \\
\hline \multicolumn{2}{|c|}{ Age in years $(\mathrm{mv} \pm \mathrm{sd})$} & $56.15 \pm 12.23$ & $55.47 \pm 10.91$ & 0.57 \\
\hline \multicolumn{2}{|c|}{ Time since HTx in years $(\mathrm{mv} \pm \mathrm{sd})$} & $7.1 \pm 5.50$ & - & - \\
\hline \multirow{3}{*}{ Smoking habits \% $(n)$} & smoker & $5.4 \%(6)$ & $17 \%(15)$ & \multirow{3}{*}{0.02} \\
\hline & nonsmoker & $74.1 \%(83)$ & $60.3 \%(54)$ & \\
\hline & former smoker & $20.5 \%(23)$ & $22.7 \%(20)$ & \\
\hline \multicolumn{2}{|c|}{ Ejection fraction in $\%(\mathrm{mv} \pm \mathrm{sd})$} & $57.31 \pm 8.04$ & $28.17 \pm 9.36$ & $<0.01$ \\
\hline \multirow{4}{*}{ Underlying heart disease $\%(n)$} & DCM & $61.6 \%(69)$ & $61.8 \%(55)$ & 0.99 \\
\hline & ICM & $31.3 \%(35)$ & $32.6 \%(29)$ & 0.88 \\
\hline & valvular insufficiency & $13.4 \%(15)$ & $38.2 \%(34)$ & $<0.01$ \\
\hline & atrial fibrillation & $6.3 \%(7)$ & $29.2 \%(26)$ & $<0.01$ \\
\hline \multirow{5}{*}{ Co-morbidities \% ( $n$ ) } & hypertension & $55.9 \%(62)$ & $74.2 \%(66)$ & 0.01 \\
\hline & diabetes mellitus & $34.8 \%(39)$ & $36 \%(32)$ & 0.88 \\
\hline & osteoporosis & $5.4 \%(6)$ & $4.5 \%(4)$ & 0.99 \\
\hline & renal insufficiency & $84.8 \%(95)$ & $44.9 \%(40)$ & $<0.01$ \\
\hline & adipositas & $51.8 \%(58)$ & $42.7 \%(38)$ & 0.21 \\
\hline \multirow{3}{*}{$\begin{array}{l}\text { Medication relevant to oral } \\
\text { conditions } \%(n)\end{array}$} & calcium-channel blocker & $25.2 \%(28)$ & $5.7 \%(5)$ & $<0.01$ \\
\hline & immunosuppression & $100 \%(112)$ & $5.7 \%(5)$ & $<0.01$ \\
\hline & bisphopshonates & $31.8 \%(35)$ & $4.6 \%(4)$ & $<0.01$ \\
\hline \multirow{6}{*}{$\begin{array}{l}\text { Blood parameters (mv } \pm s d) \\
\text { (at the time of evaluation) }\end{array}$} & $\mathrm{CRP}(\mathrm{mg} / \mathrm{L})$ & $5.40 \pm 10.49$ & $11.65 \pm 23.57$ & 0.03 \\
\hline & creatinine $(\mu \mathrm{mol} / \mathrm{L})$ & $45.88 \pm 111.78$ & $45.95 \pm 73.68$ & 0.67 \\
\hline & hemoglobin (mmol/ L) & $8.55 \pm 1.88$ & $8.23 \pm 1.76$ & 0.68 \\
\hline & erythrocytes $\left(10^{6} / \mu \mathrm{L}\right)$ & $4.53 \pm 0.62$ & $4.61 \pm 0.74$ & 0.56 \\
\hline & leukocytes $\left(10^{3} / \mu \mathrm{L}\right)$ & $6.50 \pm 1.90$ & $7.79 \pm 2.76$ & 0.01 \\
\hline & platelet $\left(10^{3} / \mu \mathrm{L}\right)$ & $214.73 \pm 77.88$ & $237.93 \pm 76.33$ & 0.07 \\
\hline \multirow{7}{*}{ NYHA class } & $\mathrm{I}$ & & $5 \%(4 / 76)$ & \multirow{7}{*}{-} \\
\hline & I-II & & $5 \%(4 / 76)$ & \\
\hline & II & & $47 \%(36 / 76)$ & \\
\hline & II-III & - & $5 \%(4 / 76)$ & \\
\hline & III & & $26 \%(4 / 76)$ & \\
\hline & III-IV & & $5 \%(4 / 76)$ & \\
\hline & IV & & $5 \%(4 / 76)$ & \\
\hline
\end{tabular}

HTx: heart transplantation, HI: heart insufficiency, CRP: c-reactive protein, mv: mean value, sd: standard deviation, DCM: dilatative cardio-myopathy, ICM: ischeamic cardio-myopathy; significant values $(p<0.05)$ are highlighted in bold.

\subsection{Questionnaires}

The results of the dental behaviour and periodontitis questionnaires are presented in Tables 2 and 3. HTx patients were significantly more often allocated to dentists than the HI group $(88.1 \%$ vs. $41.5 \% ; p<0.01$ ). Furthermore, HTx patients rated dentists' knowledge about underlying disease and their information about antibiotic prophylaxis higher than the HI group $(p<0.01)$. Additionally, HTx patients stated more often to feel informed appropriately than HI patients $(88.8 \%$ vs. $72.4 \%$, $p<0.01)$. Regarding usage of oral hygiene aids, HTx used interdental cleaning ( $33.9 \%$ vs. $15.7 \%$, $p<0.01)$ and mouth rinse $(62.5 \%$ vs. $44.9 \%, p=0.02)$ more often than the HI group (Table 2$)$. In the periodontitis questionnaire, HTx patients reported more frequently to suffer from tooth pain $(17.1 \% \mathrm{vs}$. $3.6 \%, p<0.01)$ and more compliant-oriented visits to the dentist $(25.7 \%$ vs. $11.9 \%, p=0.02$; Table 3$)$. 
Table 2. Results of the dental behaviour between groups, significance level: $p<0.05$.

\begin{tabular}{|c|c|c|c|c|}
\hline & & HTx & HI & $p$-Value \\
\hline \multicolumn{2}{|c|}{ Allocation to dentist $\%(n)$} & $88.1 \%(96 / 109)$ & $41.5 \%(34 / 82)$ & $<0.01$ \\
\hline \multicolumn{2}{|c|}{ Dental visit before $\mathrm{Tx} \%(n)$} & $82.7 \%(91 / 110)$ & - & - \\
\hline \multirow{4}{*}{$\begin{array}{l}\text { Dental treatment before Tx \% } \\
(n)\end{array}$} & tooth extraction & $26.8 \%(30 / 112)$ & & \\
\hline & restorative treatment & $55.4 \%(62 / 112)$ & - & - \\
\hline & periodontal therapy & $6.3 \%(7)$ & & \\
\hline & Control/no invasive treatment & $25 \%(28 / 112)$ & & \\
\hline \multicolumn{2}{|c|}{ Regular dental treatment \% $(n)$} & $67 \%(73 / 109)$ & $77 \%(67 / 87)$ & 0.15 \\
\hline \multicolumn{2}{|c|}{ Dentists knowledge about underlying disease \% $(n)$} & $90.9 \%(100 / 110)$ & $56.6 \%(47 / 83)$ & $<0.01$ \\
\hline \multicolumn{2}{|c|}{ Information about antibiotic prophylaxis \% $(n)$} & $74.8 \%(83 / 111)$ & $37 \%(30 / 81)$ & $<0.01$ \\
\hline \multicolumn{2}{|c|}{ Information about relationship oral-general health \% $(n)$} & $13.4 \%(15 / 112)$ & $6.7 \%(6 / 89)$ & 0.17 \\
\hline \multicolumn{2}{|c|}{ Feel informed appropriately } & $88.8 \%(95 / 107)$ & $72.4 \%(63 / 87)$ & 0.01 \\
\hline \multirow{3}{*}{ last dental examination \% $(n)$} & $0-3$ months & $33.9 \%(38 / 112)$ & $27.6 \%(24 / 87)$ & \multirow{3}{*}{0.69} \\
\hline & 3-12 months & $52.7 \%(59 / 112)$ & $57.5 \%(50 / 87)$ & \\
\hline & $>12$ months & $13.4 \%(15 / 112)$ & $14.9 \%(13 / 87)$ & \\
\hline \multirow{3}{*}{$\begin{array}{l}\text { oral hygiene: tooth brushing } \\
\qquad \%(n)\end{array}$} & $<1 x /$ day & $1.8 \%(2 / 111)$ & $4.7 \%(4 / 86)$ & \multirow{3}{*}{0.07} \\
\hline & 1-2x/day & $75.7 \%(84 / 111)$ & $83.7 \%(72 / 86)$ & \\
\hline & $>2 x /$ day & $22.5 \%(25 / 111)$ & $11.6 \%(10 / 86)$ & \\
\hline \multirow{5}{*}{ oral hygiene aids \% ( $n)$} & manual toothbrush & $64.3 \%(72 / 112)$ & $74.2 \%(66 / 89)$ & 0.17 \\
\hline & power toothbrush & $38.4 \%(43 / 112)$ & $30.3 \%(27 / 89)$ & 0.30 \\
\hline & dental floss/interdental brush & $33.9 \%(38 / 112)$ & $15.7 \%(14 / 89)$ & $<0.01$ \\
\hline & mouth rinse & $62.5 \%(70 / 112)$ & $44.9 \%(40 / 89)$ & 0.02 \\
\hline & fluoride gel & $6.3 \%(7 / 112)$ & $11.2 \%(10 / 89)$ & 0.31 \\
\hline
\end{tabular}

HTx: heart transplantation, HI: heart insufficiency; significant values $(p<0.05)$ are highlighted in bold.

Table 3. Results of the periodontitis questionnaire, significance level: $p<0.05$.

\begin{tabular}{cccc}
\hline Symptoms & HTx & HI & $p$-Value \\
\hline swollen gingiva \% $(n)$ & $13.4 \%(15 / 112)$ & $6.9 \%(6 / 87)$ & 0.17 \\
aching gums \% $(n)$ & $11.6 \%(13 / 112)$ & $14.9 \%(13 / 87)$ & 0.53 \\
sensitive gums \% $(n)$ & $25.2 \%(28 / 111)$ & $20.7 \%(18 / 87)$ & 0.50 \\
bleeding gums \% $(n)$ & $20 \%(22 / 110)$ & $28.2 \%(24 / 85)$ & 0.23 \\
Recession \% $(n)$ & $30.9 \%(34 / 119)$ & $26.7 \%(23 / 86)$ & 0.64 \\
tooth hypersensitivity \% $(n)$ & $28.8 \%(32 / 111)$ & $31 \%(27 / 87)$ & 0.76 \\
tooth mobility \% $(n)$ & $9.9 \%(11 / 111)$ & $8.1 \%(7 / 86)$ & 0.81 \\
tooth migration \% $(n)$ & $9.1 \%(10 / 110)$ & $7.1 \%(6 / 85)$ & 0.79 \\
change in occlusion \% $(n)$ & $7.2 \%(8 / 111)$ & $3.6 \%(3 / 84)$ & 0.36 \\
halitosis \% $(n)$ & $17.3 \%(19 / 110)$ & $21.2 \%(18 / 85)$ & 0.58 \\
bad taste \% $(n)$ & $16.2 \%(18 / 111)$ & $16.5 \%(14 / 85)$ & 0.99 \\
tooth pain \% $(n)$ & $17.1 \%(19 / 111)$ & $3.6 \%(3 / 83)$ & $<\mathbf{0 . 0 1}$ \\
previous periodontitis therapy \% $(n)$ & $15.5 \%(17 / 110)$ & $15.5 \%(13 / 84)$ & 0.99 \\
regular control investigation \% $(n)$ & $77.7 \%(87 / 112)$ & $77 \%(67 / 87)$ & 0.99 \\
Complaint-oriented investigation \% $(n)$ & $25.7 \%(28 / 109)$ & $11.9 \%(10 / 84)$ & $\mathbf{0 . 0 2}$ \\
regular professional tooth cleaning \% $(n)$ & $39.6 \%(44 / 111)$ & $44.7 \%(38 / 85)$ & 0.56 \\
\hline
\end{tabular}

HTx: heart transplantation, HI: heart insufficiency; significant values $(p<0.05)$ are highlighted in bold.

\subsection{Oral Examination}

The results of oral examination are given in Table 4. No differences between both groups were present regarding dental status (DMF-T) and periodontitis severity $(p>0.05)$. The dental treatment need was approximately low and comparable between HTx and HI (15.2\% vs. $15.7 \%, p=0.99)$. The periodontal treatment need was high, showing prevalence of $79.5 \%$ (HTx) and $87.6 \%(\mathrm{HI}, p=0.14)$, respectively (Table 4). 
Table 4. Oral health situation between the two groups, significance level: $p<0.05$.

\begin{tabular}{|c|c|c|c|c|}
\hline \multicolumn{2}{|c|}{ Parameter } & $\operatorname{HTx}(n=112)$ & HI $(n=89)$ & $p$-Value \\
\hline \multicolumn{2}{|c|}{ DMF-T $(\mathrm{mv} \pm \mathrm{sd})$} & $16.93 \pm 7.52$ & $17.78 \pm 7.06$ & 0.46 \\
\hline \multicolumn{2}{|c|}{$\mathrm{D}-\mathrm{T}(\mathrm{mv} \pm \mathrm{sd})$} & $0.26 \pm 0.74$ & $0.28 \pm 0.75$ & 0.88 \\
\hline \multicolumn{2}{|c|}{$\mathrm{M}-\mathrm{T}(\mathrm{mv} \pm \mathrm{sd})$} & $8.41 \pm 8.88$ & $8.94 \pm 9.22$ & 0.68 \\
\hline \multicolumn{2}{|c|}{$\mathrm{F}-\mathrm{T}(\mathrm{mv} \pm \mathrm{sd})$} & $8.26 \pm 5.54$ & $8.55 \pm 5.66$ & 0.75 \\
\hline \multicolumn{2}{|c|}{ Gingival overgrowth \% $(n)$} & $6 \%(7)$ & 0 & $<0.01$ \\
\hline \multirow{3}{*}{ Perio-dontitis \% $(n)$} & no/mild & $21.4 \%(24)$ & $22.5 \%(20)$ & \multirow{3}{*}{0.28} \\
\hline & moderate & $50.9 \%(57)$ & $40.4 \%(36)$ & \\
\hline & severe & $27.7 \%(31)$ & $37.1 \%(33)$ & \\
\hline \multirow{3}{*}{\multicolumn{2}{|c|}{$\begin{array}{l}\text { dental treatment need } \%(n) \\
\text { periodontal treatment need } \%(n) \\
\text { overall treatment need } \%(n)\end{array}$}} & $15.2 \%(17)$ & $15.7 \%(14)$ & 0.99 \\
\hline & & $79.5 \%(89)$ & $87.6 \%(78)$ & 0.14 \\
\hline & & $80.4 \%(90)$ & $87.6 \%(78)$ & 0.18 \\
\hline
\end{tabular}

HTx: heart transplantation, HI: heart insufficiency, mv: mean value, sd: standard deviation; significant values $(p<0.05)$ are highlighted in bold.

Furthermore, the presence of swollen gingiva $(p=0.03)$, bleeding gums $(p<0.01)$, and the attendance to regular professional tooth cleaning $(p<0.01)$ in the periodontitis questionnaire was associated with periodontal treatment need in the total cohort (Table 5).

Table 5. Association between periodontitis questionnaire and periodontal treatment need within the total cohort; significance level: $p<0.05$.

\begin{tabular}{cc}
\hline Symptoms & $p$-Value \\
\hline swollen gingiva & $\mathbf{0 . 0 3}$ \\
aching gums & 0.99 \\
sensitive gums & 0.12 \\
bleeding gums & $<\mathbf{0 . 0 1}$ \\
recession & 0.15 \\
tooth hypersensitivity & 0.42 \\
tooth mobility & 0.32 \\
tooth migration & 0.99 \\
change in occlusion & 0.99 \\
halitosis & 0.46 \\
bad taste & 0.12 \\
tooth pain & 0.77 \\
previous periodontitis therapy & 0.43 \\
regular control investigation & 0.26 \\
Complaint-oriented investigation & 0.63 \\
regular professional tooth cleaning & $<\mathbf{0 . 0 1}$ \\
\hline Significant values $(p<0.05)$ are highlighted in bold
\end{tabular}

\section{Discussion}

Summary of the main results: HTx patients were found to present a slightly improved dental behaviour compared to the HI group. However, HTx recipients reported little more complaints and complaint-oriented dentist consultations in the periodontitis questionnaire. Especially, the periodontal treatment need was high for both groups, whereby oral health status was comparable between HTx and HI group. Considering the total cohort, the presence of swollen and bleeding gums rated in the questionnaire showed an association with periodontal treatment need.

Comparison with the literature: The current study did not include a healthy control group. As performed previously [8-10], the oral conditions in general can be interpreted considering the results of the Fifth German Oral Health Study (DMS V), a representative study for the German general population [20]. While the mean age of participants in the current study was on average approximately 
56 years, this age group is not exclusively reflected in the DMS V. The slightly higher age group of 65-74 years in the DMS V showed a DMF-T of 17.7, a D-T of 0.5, and an M-T of 11.1, which is almost comparable to the current study's findings (Table 6) [20]. Accordingly, a comparable dental status to healthy general population can be assumed for both HI and HTx patients. The prevalence of $64.4 \%$ of moderate to severe periodontitis reported in DMS V appears slightly lower than for the current study's participants. Similarly, considering a periodontal treatment need of $75.4 \%$ of general population (DMS V), this seems also slightly higher in the both groups within the current study. Accordingly, a high periodontal treatment need of patients with HI and after HTx, which is almost higher than for the German general population in the DMS V [20] can be concluded. This result is in line with a recent Chinese cross-sectional study, which presented worse periodontal conditions for HTx recipients, while dental care status was comparable to healthy controls [12]. Similarly, patients who received a solid organ transplantation (kidney, liver, lung) were found to present high periodontal treatment need, irrespective of time since transplantation [7-11]. Different explanations might be applicable for this situation for the patients in the current study. On the one hand, HI and HTx might influence the periodontitis pathogenesis in the affected patients. Schulze-Späte et al. presented an increase in turnover markers of the alveolar bone of patients with heart insufficiency compared to healthy controls [21]. Furthermore, there are associations between periodontitis and coronary heart diseases, which are already well documented in the literature [22]. Besides inflammatory effects and a role of potentially periodontal bacteria, a shared risk complex, including smoking and metabolic disorders could link heart diseases and periodontitis $[22,23]$. The importance of these factors for the current study's findings are difficult to estimate.

Table 6. Comparison of dental findings with the Fifth German Oral Health Study (DMS V) (Jordan et al. 2016).

\begin{tabular}{|c|c|c|c|c|c|}
\hline \multicolumn{2}{|c|}{ Parameter } & $\operatorname{HTx}(n=112)$ & HI $(n=89)$ & $\begin{array}{l}\text { DMS V Age } \\
\text { Group 35-44 Years }\end{array}$ & $\begin{array}{c}\text { DMS V Age } \\
\text { Group 65-74 Years }\end{array}$ \\
\hline \multicolumn{2}{|c|}{ DMF-T $(m v \pm s d)$} & $16.9 \pm 7.5$ & $17.8 \pm 7.1$ & 11.2 & 17.7 \\
\hline \multicolumn{2}{|c|}{$\mathrm{D}-\mathrm{T}(\mathrm{mv} \pm \mathrm{sd})$} & $0.3 \pm 0.7$ & $0.3 \pm 0.8$ & 0.5 & 0.5 \\
\hline \multicolumn{2}{|c|}{$\mathrm{M}-\mathrm{T}(\mathrm{mv} \pm \mathrm{sd})$} & $8.4 \pm 8.9$ & $8.9 \pm 9.2$ & 2.1 & 11.1 \\
\hline \multicolumn{2}{|c|}{$\mathrm{F}-\mathrm{T}(\mathrm{mv} \pm \mathrm{sd})$} & $8.3 \pm 5.5$ & $8.6 \pm 5.7$ & 8.6 & 6.1 \\
\hline \multirow{3}{*}{$\begin{array}{c}\text { Periodontitis \% } \\
(n)\end{array}$} & no/mild & $21 \%$ & $23 \%$ & $48 \%$ & $35 \%$ \\
\hline & moderate & $51 \%$ & $40 \%$ & $43 \%$ & $45 \%$ \\
\hline & severe & $28 \%$ & $37 \%$ & $8 \%$ & $20 \%$ \\
\hline
\end{tabular}

HTx: heart transplantation, HI: heart insufficiency, mv: mean value, sd: standard deviation.

The more relevant point might be the dental care situation of patients with HI and after HTx. While majority of HTx recipients stated that they have been allocated to a dentist prior to HTx, only the vast minority have received periodontal therapy from their dentist. This might indicate a gap in dental care, regarding periodontal rehabilitation of HTx candidates and recipients. This situation is critical, because periodontal inflammation leads to increased permeability of periodontal tissue [24], which is associated with an increased risk for bacteraemia caused by chewing, oral hygiene measures, and dental therapy procedures $[25,26]$. Transplant recipients are under a lifelong immunosuppressive medication with an increased risk of systemic infections [1,2]; thus, the high periodontal treatment need might be a serious risk for their systemic health.

The HTx recipients within the current study were found to present a slightly improved dental behaviour. Thereby, the HTx group appears to be informed well about antibiotic prophylaxis and subjectively feel informed better than HI group. Furthermore, the usage of aids for interdental cleaning was higher in the HTx than in the HI group, although it was still approximately low. A similar tendency was previously found for kidney and liver transplanted individuals, respectively [8,9]. The low usage of interdental cleaning aids might be a further reason for the high periodontal treatment need, as interdental cleaning devices reduce inflammation more effectively than brushing alone [27]. Moreover, 
only a minority of patients used a power toothbrush, although this would be recommendable for periodontally diseased patients [28]. In summary, although HTx showed slightly better oral behaviour than the HI group, a lack in appropriate information and/or patient motivation must be assumed. In combination with the high treatment need, the demand of special care programs, which is already pointed to in the literature [6], can be supported by the current study.

Another aspect was the applied periodontitis questionnaire. This validated tool can reflect the presence of periodontal complaints and inflammation [14]. For the total cohort, bleeding and swollen gums were associated with the presence of periodontal treatment need. The absence of further associations might be caused by the generally high prevalence of periodontal treatment need. However, and regardless, transplant centres might use these questions about bleeding and swelling of the gums for their patients to detect high-risk patients with the necessity of allocation to the dentist.

Strengths and limitations: This current study is the first and largest examination of patients with $\mathrm{HI}$ and after HTx in Germany. The standardized examination and application of valid questionnaires strengthens the findings. Furthermore, the focus on treatment need and the potential application of periodontal complaint-related questions for HTx recipients are an approach with clinical potential. However, there are several limitations to address. The cross-sectional design limits the ability to draw any causative conclusions. The absence of a healthy control group must also be mentioned, although the comparison to representative study is a repeatedly applied and functioning concept [7-10]. Furthermore, the occurrence of infectious complications due to the high periodontal treatment need stays unclear. The analysis of blood values related to periodontal treatment need would be an interesting approach, as a recent study found the CRP to be related to periodontal inflammation [13]. Nevertheless, this was beyond the focus of the current study, which aimed at the assessment of the recent care situation of HTx and HI patients. A further influential factor that has to be considered in the interpretation of periodontal findings is the difference in smoking habits, comorbidities, and medication between HI and HTx. A matching would have been helpful; however, it was aimed to include as many patients as possible. Moreover, the assessment of periodontitis is limited by the fact that the new classification for periodontal and peri-implant diseases and conditions with a staging and grading matrix [29] was not applied. The usage of this recent classification scheme is recommended for scientific evaluation of periodontitis and should be applied accordingly [29]. However, at the time when the current study was planned and executed, this new classification was not available. For appropriate staging and grading, many diagnostic findings (e.g., furcation, tooth mobility, radiographic bone loss) as well as rate of progression are needed. Therefore, these necessary data have not been recorded completely and progression rate was not detectable within a cross-sectional study. Thus, the periodontitis severity was determined according to Eke et al. 2012 [17], which is validated even in cohorts of patients with general diseases [8-10] and used in the DMS V as a reference for German general population [20].

\section{Conclusions}

Patients with HI and after HTx show a high periodontal treatment need. While HTx recipients show a slightly improved oral behaviour, a lack in information can be assumed. A special care program for HTx candidates and recipients appears necessary and should include early pretransplant rehabilitation and sufficient maintenance after HTx.

Author Contributions: Conceptualization, C.B., G.S., J.G. and D.Z.; Data curation, C.B., J.W., M.E. and J.R.; Formal analysis, T.K.; Investigation, J.W., M.E. and J.R.; Methodology, C.B., G.S., J.G. and D.Z.; Project administration, C.B., J.G. and D.Z.; Supervision, J.G. and D.Z.; Writing-original draft, C.B., J.W., G.S. and D.Z.; Writing-review \& editing, C.B., J.W., G.S., M.E., J.R., T.K., A.O., M.A.B., R.H. and J.G.

Acknowledgments: We would like to thank the medical team of the University Department for Cardiac Surgery, Leipzig Heart Center, Leipzig, Germany for organizing the patient management. The authors acknowledge support from the German Research Foundation (DFG) and Leipzig University within the program of Open Access Publishing.

Conflicts of Interest: All participating authors declare no conflict of interest. 


\section{References}

1. Lund, L.H.; Edwards, L.B.; Dipchand, A.I.; Goldfarb, S.; Kucheryavaya, A.Y.; Levvey, B.J.; Meiser, B.; Rossano, J.W.; Yusen, R.D.; Stehlik, J.; et al. The Registry of the International Society for Heart and Lung Transplantation: Thirty-third Adult Heart Transplantation Report-2016; Focus Theme: Primary Diagnostic Indications for Transplant. J Heart Lung Transplant. 2016, 35, 1158-1169. [CrossRef] [PubMed]

2. Khush, K.K. Personalized treatment in heart transplantation. Curr. Opin. Organ Transplant. 2017, 22, $215-220$. [CrossRef] [PubMed]

3. Furiasse, N.; Kobashigawa, J.A. Immunosuppression and adult heart transplantation: Emerging therapies and opportunities. Expert Rev. Cardiovasc. Ther. 2017, 15, 59-69. [CrossRef] [PubMed]

4. Kumar, P.S. Oral microbiota and systemic disease. Anaerobe 2013, 24, 90-93. [CrossRef] [PubMed]

5. Maestre-Vera, J.R.; Gómez-Lus Centelles, M.L. Antimicrobial prophylaxis in oral surgery and dental procedures. Med. Oral Cir. Bucal. 2006, 12, E45-E52.

6. Rustemeyer, J.; Bremerich, A. Necessity of surgical dental foci treatment prior to organ transplantation and heart valve replacement. Clin. Oral Investig. 2007, 11, 171-174. [CrossRef] [PubMed]

7. Ziebolz, D.; Hraský, V.; Goralczyk, A.; Hornecker, E.; Obed, A.; Mausberg, R.F. Dental care and oral health in solid organ transplant recipients: A single center cross-sectional study and survey of German transplant centers. Transpl. Int. 2011, 24, 1179-1188. [CrossRef] [PubMed]

8. Schmalz, G.; Kauffels, A.; Kollmar, O.; Slotta, J.E.; Vasko, R.; Müller, G.A.; Haak, R.; Ziebolz, D. Oral behavior, dental, periodontal and microbiological findings in patients undergoing hemodialysis and after kidney transplantation. BMC Oral Health 2016, 16, 72. [CrossRef] [PubMed]

9. Kauffels, A.; Schmalz, G.; Kollmar, O.; Slotta, J.E.; Weig, M.; Groß, U.; Bader, O.; Ziebolz, D. Oral findings and dental behaviour before and after liver transplantation-A single-centre cross-sectional study. Int Dent. J. 2017, 67, 244-251. [CrossRef]

10. Marcinkowski, A.; Ziebolz, D.; Kleibrink, B.E.; Weinreich, G.; Kamler, M.; Teschler, H.; Sommerwerck, U. Deficits in oral health behavior and oral health status in patients after lung transplantation. Clin. Respir. J. 2018, 12, 721-730. [CrossRef]

11. Schmalz, G.; Wendorff, H.; Berisha, L.; Meisel, A.; Widmer, F.; Marcinkowski, A.; Teschler, H.; Sommerwerck, U.; Haak, R.; Kollmar, O.; et al. Association between the time after transplantation and different immunosuppressive medications with dental and periodontal treatment need in patients after solid organ transplantation. Transpl. Infect. Dis. 2018, 20, e12832. [CrossRef]

12. Cao Chen, X.; Jia, Y.; Lv, Y.; Sun, Z. Oral health status of adult heart transplant recipients in China: A cross-sectional study. Medicine (Baltimore) 2018, 97, e12508.

13. Sezgin, Y.; Bulut, Ş.; Bozalığlu, S.; Sezgin, A. Levels of High-Sensitivity C-Reactive Protein in Heart Transplant Patients with and Without Periodontitis. Exp. Clin. Transplant. 2019, 17, 123-127. [CrossRef] [PubMed]

14. Ng, S.K.S.; Leung, W.K. Oral health-related quality of life and periodontal status. Community Dent. Oral Epidemiol. 2006, 34, 114-122. [CrossRef] [PubMed]

15. Wilson, W.; Taubert, K.A.; Gewitz, M.; Lockhart, P.B.; Baddour, L.M.; Levison, M.; Bolger, A.; Cabell, C.H.; Takahashi, M.; Baltimore, R.S.; et al. Prevention of infective endocarditis: Guidelines from the American Heart Association: A guideline from the American Heart Association Rheumatic Fever, Endocarditis, and Kawasaki Disease Committee, Council on Cardiovascular Disease in the Young, and the Council on Clinical Cardiology, Council on Cardiovascular Surgery and Anesthesia, and the Quality of Care and Outcomes Research Interdisciplinary Working Group. Circulation 2007, 116, 1736-1754.

16. WHO. Oral Health Surveys, Basic Methods, 4th ed.; Oral Health Unit, WHO: Geneva, Switzerland, 1997.

17. Eke, P.I.; Page, R.C.; Wei, L.; Thornton-Evans, G.; Genco, R.J. Update of the case definitions for population-based surveillance of periodontitis. J. Periodontol. 2012, 83, 1449-1454. [CrossRef]

18. Diamanti-Kipioti, A.; Papapanou, T.N.; Moraitaki-Zamitsai, A.; Lindhe, J.; Mitsis, F. Comparative estimation of periodontal conditions by means of different index systems. J. Clin. Periodontol. 1993, 20, 656. [CrossRef]

19. Meyle, J.; Jepsen, S. The Periodontal Screening-Index (PSI). Parodontologie 2000, 11, 17-21. (In German)

20. Jordan, R.A.; Micheelis, W. The Fifth German Oral Health Study (DMS V); Institut der Deutschen Zahnärzte (Hrsg.) (IDZ Materialienreihe Band 35), Deutscher Zahnärzte Verlag DÄV: Köln, Germany, 2016. (In German) 
21. Schulze-Späte, U.; Mizani, I.; Salaverry, K.R.; Chang, J.; Wu, C.; Jones, M.; Kennel, P.J.; Brunjes, D.L.; Choo, T.H.; Kato, T.S.; et al. Periodontitis and bone metabolism in patients with advanced heart failure and after heart transplantation. ESC Heart Fail. 2017, 4, 169-177. [CrossRef]

22. Li, C.; Lv, Z.; Shi, Z.; Zhu, Y.; Wu, Y.; Li, L.; Iheozor-Ejiofor, Z. Periodontal therapy for the management of cardiovascular disease in patients with chronic periodontitis. Cochrane Database Syst. Rev. 2017, 11, CD009197. [CrossRef]

23. Bartova, J.; Sommerova, P.; Lyuya-Mi, Y.; Mysak, J.; Prochazkova, J.; Duskova, J.; Janatova, T.; Podzimek, S. Periodontitis as a risk factor of atherosclerosis. J. Immunol. Res. 2014, 2014, 636893. [CrossRef] [PubMed]

24. Curtis, M.A. Periodontal microbiology-The lid's off the box again. J. Dent. Res. 2014, 93, 840-842. [CrossRef] [PubMed]

25. Zhang, W.; Daly, C.G.; Mitchell, D.; Curtis, B. Incidence and magnitude of bacteraemia caused by flossing and by scaling and root planing. J. Clin. Periodontol. 2013, 40, 41-52. [CrossRef] [PubMed]

26. Tomás, I.; Diz, P.; Tobías, A.; Scully, C.; Donos, N. Periodontal health status and bacteraemia from daily oral activities: Systematic review/meta-analysis. J. Clin. Periodontol. 2012, 39, 213-228. [CrossRef]

27. Worthington, H.V.; MacDonald, L.; Poklepovic Pericic, T.; Sambunjak, D.; Johnson, T.M.; Imai, P.; Clarkson, J.E. Home use of interdental cleaning devices, in addition to toothbrushing, for preventing and controlling periodontal diseases and dental caries. Cochrane Database Syst. Rev. 2019, 4, CD012018. [CrossRef]

28. Yaacob, M.; Worthington, H.V.; Deacon, S.A.; Deery, C.; Walmsley, A.D.; Robinson, P.G.; Glenny, A.M. Powered versus manual toothbrushing for oral health. Cochrane Database Syst. Rev. 2014, 6, CD002281. [CrossRef]

29. Caton, J.; Armitage, G.; Berglundh, T.; Chapple, I.L.C.; Jepsen, S.; Kornman, K.S.; Mealey, B.L.; Papapanou, P.N.; Sanz, M.; Tonetti, M.S. A new classification scheme for periodontal and peri-implant diseases and conditions-Introduction and key changes from the 1999 classification. J. Clin. Periodontol. 2018, 45, S1-S8. [CrossRef]

(C) 2019 by the authors. Licensee MDPI, Basel, Switzerland. This article is an open access article distributed under the terms and conditions of the Creative Commons Attribution (CC BY) license (http://creativecommons.org/licenses/by/4.0/). 